\title{
SISTEM KONTROL KONVEYOR PEMILAH LOGAM MENGGUNAKAN PLC OMRON CP1E
}

\section{METAL SECTOR CONVEYOR CONTROL SYSTEM USING PLC OMRON CP1E}

\author{
Alimuddin ${ }^{1}$, Sonny Rumalutur ${ }^{2}$, Marcos Mambrisauw $^{3}$ \\ ${ }^{1}$ Politeknik Saint Paul \\ ${ }^{2}$ Politeknik Saint Paul \\ ${ }^{3}$ Politeknik Saint Paul \\ ${ }^{1}$ ghailan11@ rocketmail.com, ${ }^{2}$ sonny_r@poltekstpaul.ac.id, ${ }^{3}$ marcos.mambrisauw@gmail.com
}

\begin{abstract}
Abstrak
Penelitian yang dilakukan bertujuan untuk membuat sistem kontrol pemilah logam secara otomatis menggunakan PLC Omron CP1E30 dengan program ladder diagram yang dirancang dengan aplikasi CX-Programmer

Masukan PLC yang digunakan terdapat satu buah sensor proximity dan dua buah sensor photoelektrik sedangkan keluarannya terdapat dua buah motor penggerak konveyor dan satu buah solenoid. Sensor proximity berfungsi untuk mendeteksi benda logam dan bukan logam dan sensor photoelektrik berfungsi untuk mendeteksi adanya suatu benda yang melaluinya.. Keluaran PLC terdapat dua buah motor konveyor berfungsi membawa benda yang akan dipisahkan dan selenoid yang berfungsi memisahkan benda logam dan bukan logam

Berdasarkan hasil pengujian ternyata sistem dapat berfungsi dengan baik dimana pada saat PLC diaktifkan maka motor konveyor 1 akan aktif untuk membawa benda yang akan dipilah, pada saat benda melewati photoelectric sensor 1 maka motor konveyor 1 akan berhenti untuk dideteksi oleh proximity sensor, apabila benda tersebut adalah non logam maka motor konveyor 2 akan membawa benda non logam tersebut sampai di ujung konveyor 2, setelah benda non logam itu di deteksi oleh photoelectric sensor 2, maka motor konveyor 1 aktif kembali untuk mengantarkan benda selanjutnya. apabila proximity sensor mendeteksi benda tersebut adalah logam maka selenoid di aktifkan sehingga memisahkan benda logam tersebut..
\end{abstract}

\section{Kata kunci : Pemilah Logam, Proximity sensor, Photoelektrik sensor, Motor, Selenoid}

\begin{abstract}
The research conducted aims to create an automatic metal sorting control system using the PLC Omron CP1E30 with a ladder diagram program designed with the CX-Programmer application.

The PLC input used contains one proximity sensor and two photoelectric sensors, while the output includes two conveyor motors and a solenoid.

The proximity sensor functions to detect metal and non-metal objects and the photoelectric sensor functions to detect the presence of an object passing through it. PLC output contains two conveyor motors that carry objects to be separated and selenoid which functions to separate metal and nonmetal objects.
\end{abstract}


Based on the test results it turns out that the system can function properly where when the PLC is activated, the conveyor motor 1 will be active to carry the object to be sorted, when the object passes the photoelectric sensor 1 , the conveyor motor 1 will stop to be detected by the proximity sensor, if the object is non-metal, the conveyor motor 2 will carry the non-metal object to the end of the conveyor 2, after the non-metal object is detected by photoelectric sensor 2, the conveyor motor 1 activates again to deliver the next object. If the proximity sensor detects that the object is metal, the selenoid is activated so that it separates the metal object.

Keywords: Keywords: Metal Sorting, Proximity sensor, Photoelectric sensor, Motor, Selenoid

\section{PENDAHULUAN}

Perkembangan ilmu pengetahuan dan teknologi yang semakin maju banyak memberikan manfaat untuk memenuhi kebutuhan hidup manusia. Perkembangan teknologi yang pesat ini ditandai dengan banyaknya peralatan yang telah diciptakan dan dioperasikan baik secara manual maupun otomatis.

Dimana dalam teknologi elektronika dan komputer, menjadi acuan agar setiap langkah dalam penggunaan dan pemanfaatan teknologi diharapkan dapat mencapai hasil yang optimal baik dalam kualitas maupun kuantitasnya. Agar dapat mewujudkan hal tersebut, maka diperlukan sebuah alat, komponen atau sistem yang dapat memproses suatu data dengan cepat dan akurat.

Dengan teknologi di bidang elektronika dan komputer yang telah berkembang, maka banyak hal yang dapat dilakukan dengan cepat dan tepat untuk memenuhi kebutuhan manusia. Salah satu penggunaannya yang tak kalah penting adalah penerapan sistem kendali berbasis PLC (Programmable Logic Controller) yang mampu memberikan dampak positif dalam berbagai perangkat listrik dan elektronik di masyarakat maupun di Industri.

Selain jumlah produksi lebih banyak, biaya pengoperasiannya juga dapat ditekan seminim mungkin serta membutuhkan tenaga yang lebih sedikit, sehingga proses produksi tersebut memperoleh keuntungan lebih tinggi. Berdasarkan pertimbangan-pertimbangan diatas, untuk menunjang proses otomatis agar faktor-faktor produksi dapat dicapai dibutuhkan sistem kontrol

\section{DASAR TEORI /MATERIAL DAN METODOLOGI/PERANCANGAN}

\subsection{Programmable Logic Controller (PLC)}

Programmable Logic Controller (PLC) adalah elektronik yang mudah digunakan (user friendly) yang memiliki fungsi kendali untuk berbagai tipe dan tingkat kesulitan yang beraneka ragam. Definisi Programmable Logic Controller adalah sistem elektonik yang beroperasi secara digitaldan didesain untuk pemakaian di lingkungan Industri, dimana sistem ini menggunakan memori yang dapat diprogram untuk penyimpanan secara internal instruksi-instruksi yang mengimplementasikan fungsi-fungsi spesifik seperti logika, urutan, perwaktu, pencacahan dan operasi melalui modul-model I/O di gital maupun analog.. PLC ini dirancang untuk menggantikan suatu rangkaian relai sequensual dalam suatu sistem kontrol.

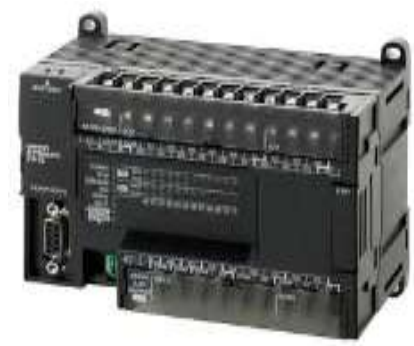

Gambar 1. PLC Omron Type CP1E 


\subsection{Bahasa Pemrograman PLC}

Agar PLC dapat berjalan sesuai dengan yang dihendaki, maka diperlukan suatu perangkat lunak (software) untuk memprogram PLC. PLC memiliki 2 bahasa pemograman yaitu dengan diagram tangga dan statemen list/mneuminic. Bahasa pemograman yang biasa dipakai adalah diagram tangga, karena lebih muda untuk dimengrti dan langkah-langkah programnya lebih mudah ditelusuri.

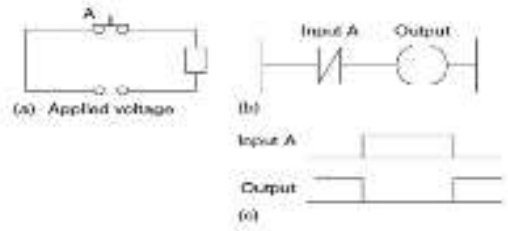

Gambar 2 memperlihatkan bentuk dari diagram tangga

Di mana bentuknya menyerupai tangga yang terdiri dari dua buah garis vertikal dan anak tangga (rung) yang terdiri dari garis horizontal. Garis-garis ini dapat dianalogikan sebagai jaringan listrik dengan garis vertikal sebelah kiri merupakan terminal positif sumber tegangan sedangkan garis vertikal sebelah kanan mewakili ground dan arus listrik akan mengalir ke masing-masing rung dari arah kiri ke kanan

\subsection{Motor DC}

Motor listrik merupakan perangkat elektromagnetis yang mengubah energi listrik menjadi energi mekanik. Energi mekanik ini digunakan untuk, misalnya memutar impeller pompa, fan atau blower, menggerakan kompresor, mengangkat bahan,dll. Motor listrik digunakan juga di rumah (mixer, bor listrik, fan angin) dan di industri. Motor listrik kadangkala disebut "kuda kerja" nya industri sebab diperkirakan bahwa motor-motor menggunakan sekitar $70 \%$ beban listrik total di industri.

Prinsip kerja dari arus searah adalah membalik phasa tegangan dari gelombang yang mempunyai nilai positif dengan menggunakan komutator, dengan demikian arus yang berbalik arah dengan kumparan jangkar yang berputar dalam medan magnet.
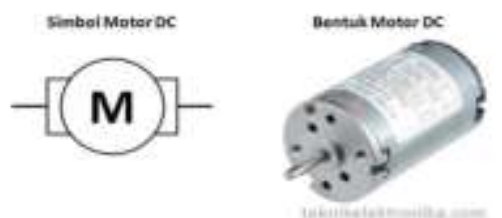

Gambar 3. Motor DC

\subsection{Sensor Photoelektrik}

Photoelectric Sensor adalah sensor yang bekerja dengan prinsip seperti transistor sebagai saklar. Energi cahaya akan diubah menjadi suatu sinyal listrik. Adanya suatu reflector yang berfungsi untuk memantulkan cahaya yang dipancarkan oleh Photoelectric .

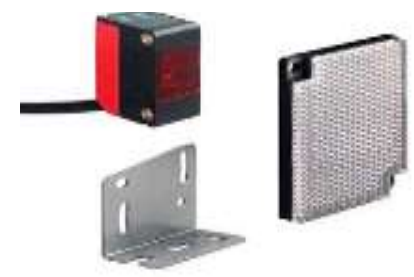

Gambar 4. Sensor Photoelectric 


\subsection{Proximity Sensor}

Proximity sensor adalah sebuah alat yang mampu mendeteksi keberadaan logam dalam jarak tertentu. Meteal detector berfungsi untuk menemukan logam tersembunyi, atau yang sulit dijangkau dengan mata kita sendiri. Metal detektor secara efektif dapat mendektesi logam yang terhalang dari tanah kayu dan bahan non logam.

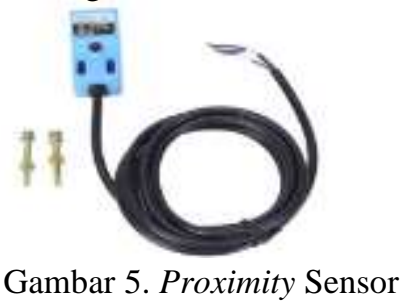

\subsection{Selenoid Proporsional}

Termasuk dalam kategori solenoida adalah sirkuit magnetik yang dirancang unik yang mempengaruhi posisi analog dari plunger atau armature solenoid sebagai fungsi arus koil. Solenoida ini, baik aksial atau putar, menggunakan fluks yang membawa geometri yang keduanya menghasilkan gaya awal yang tinggi (torsi), dan memiliki bagian yang cepat mulai menjenuhkan secara magnetic.

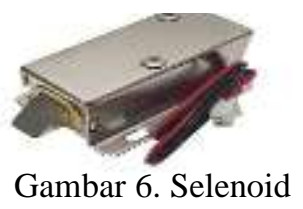

\section{PEMBAHASAN}

\subsection{Perancangan Perangkat Keras}

Modul trainer yang digunakan sebagai media pembelajaran, akan masuk ke sistem modul PLC dan digunakan sebagai penginputan data dan pengoperasian sistem, sistem I/O (input/output) pada PLC membutuhkan tegangan sebesar $24 \mathrm{~V}$ untuk menjalankan I/O nya.

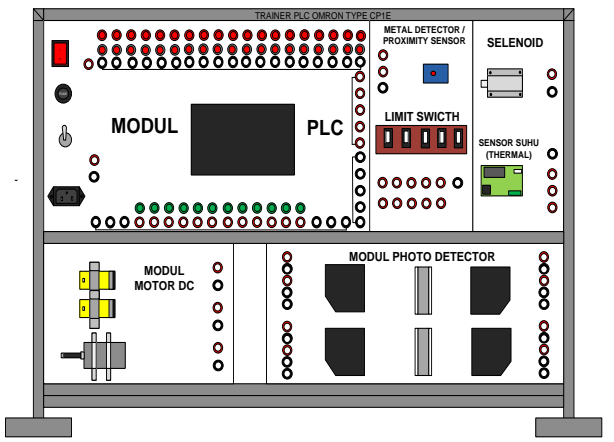

Gambar 7. Modul Trainer PLC Omron Type CP1E

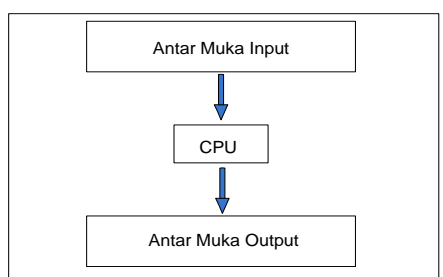

Gambar 8. Diagram Blok Perancangan Rangkaian Antar Muka. 


\subsection{Perancangan Perangkat Lunak}

untuk menjalankan sistem pengontrolan menggunakan PLC di butuhkan perangkat lunak sistem (software) sebagai bahasa pemograman. Perancangan perangkat lunak (software) yang digunakan PLC Omron type CP1E yaitu Software CX-Programmer

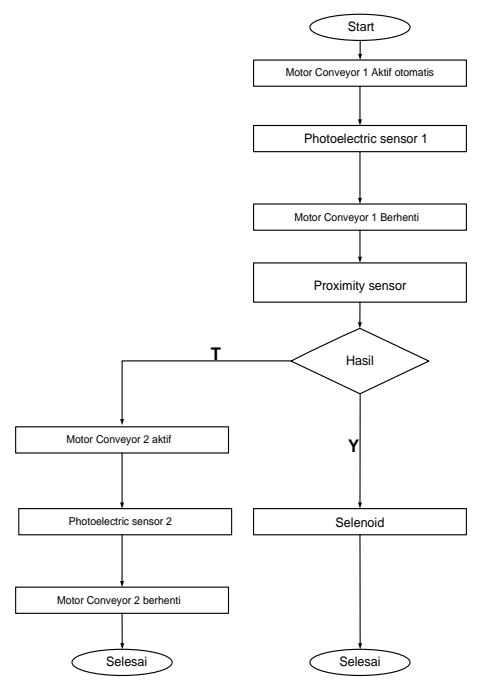

Gambar 9. Flowchart cara kerja konveyor pemilah logam

\subsection{Pengujian Proximity Sensor}

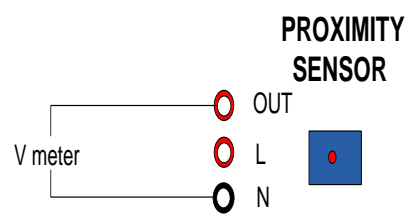

Gambar 10. Pengukuran Tegangan Pada Sensor Logam
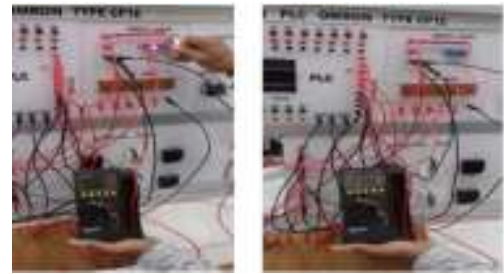

Gambar 11. Hasil Pengukuran Pada Sensor Logam

Tabel 1. Pengukuran Tegangan pada selenoid

\begin{tabular}{lc}
\hline Keadaan selenoid & Tegangan (volt) \\
\hline Tidak Terdeteksi logam & 24.06 \\
\hline Terdeteksi logam & 00.01 \\
\hline
\end{tabular}

Hasil Perhitungan Persentasi error

$$
\begin{aligned}
& \% \text { Error }=\frac{\text { Hasil Seharusnya }- \text { Hasil Pengukuran }}{\text { Hasil Seharusnya }} \times 100 \% \\
& \% \text { Error }=\frac{24-24.06}{24} \times 100 \%=0,25 \%
\end{aligned}
$$




\subsection{Pengujian Photoelectric Sensor}

MODUL PHOTO DETECTOR

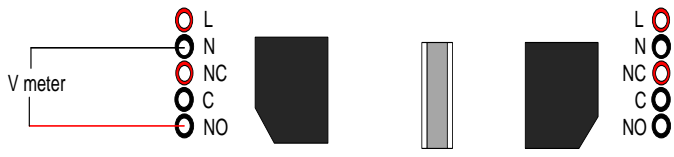

Gambar 12. Pengukuran tegangan pada Photoelectric Sensor

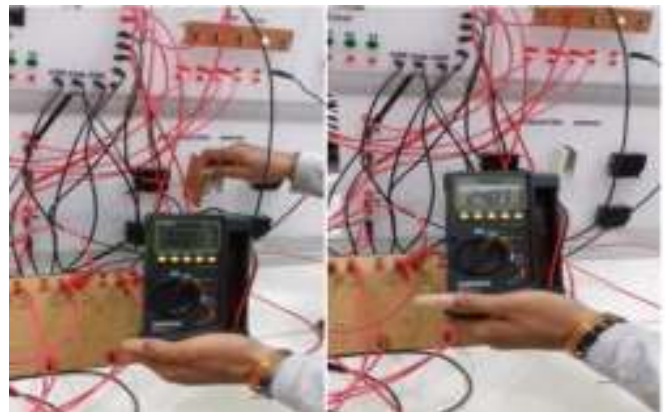

Gambar 13. Hasil Pengukuran pada Photo Electric Sensor

Tabel 2. Pengukuran Tegangan pada Photoelectric Sensor

\begin{tabular}{lc}
\hline Keadaan Photoelectric Sensor & Tegangan (volt) \\
\hline Tidak Terdeteksi benda & 24.07 \\
\hline Terdeteksi benda & 00.01 \\
\hline
\end{tabular}

Hasil Perhitungan Persentasi error :

$$
\% \text { Error }=\frac{24-24.07}{24} \times 100 \%=0,29 \%
$$

\subsection{Pengujian Motor DC}

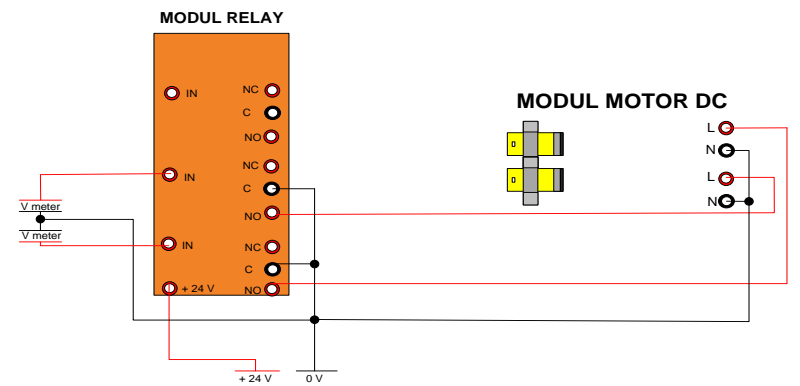

Gambar 14. Pengukuran tegangan pada motor DC

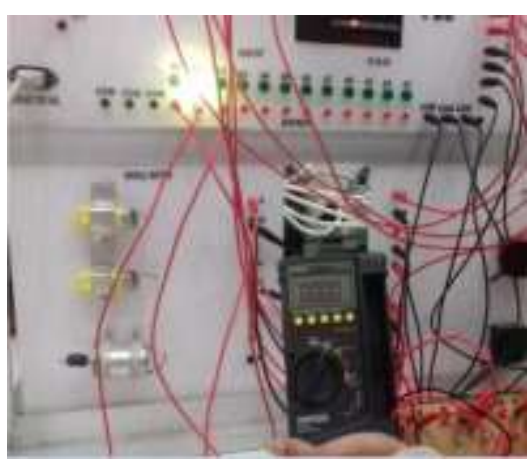

Gambar 15. Hasil Pengukuran pada motor DC 1 
JEC Vol. 6 No. 2

Jurnal Electro Luceat [November $][2020]$

Tabel 3. Pengukuran Tegangan pada motor DC

\begin{tabular}{lc}
\hline Keadaan motor DC & Tegangan (volt) \\
\hline Motor DC Tidak bekerja & 24.07 \\
\hline Motor DC bekerja & 00.00 \\
\hline
\end{tabular}

Hasil Perhitungan Persentasi error:

$\%$ Error $=\frac{24-24.07}{24} \times 100 \%=0,29 \%$

\subsection{Pengujian Diagram Ladder Conveyor Pemilah Logam}

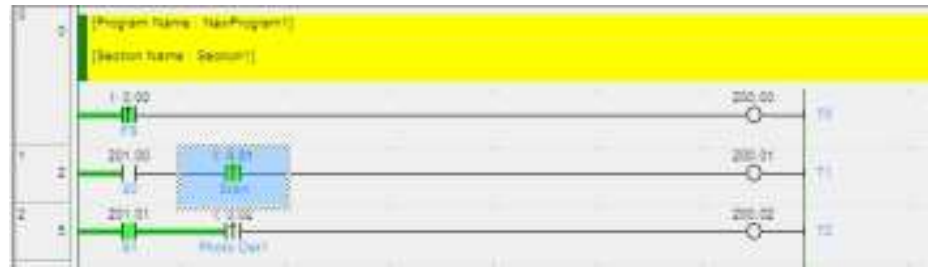

Gambar 16. Diagram ladder pada saat program dijalankan

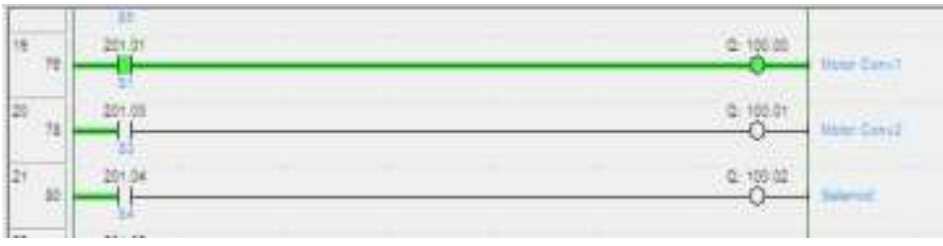

Gambar 17. Diagram ladder pada saat motor conveyor 1 bekerja

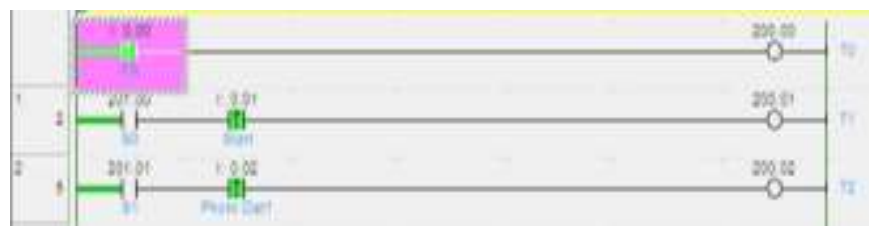

Gambar 18. Diagram ladder pada saat photo detektor 1 bekerja

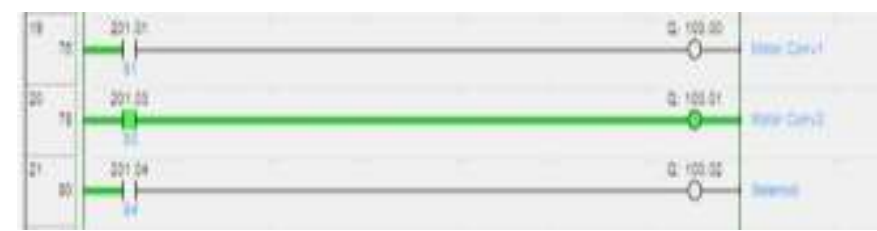

Gambar 19. Diagram ladder pada saat motor conveyor 2 bekerja

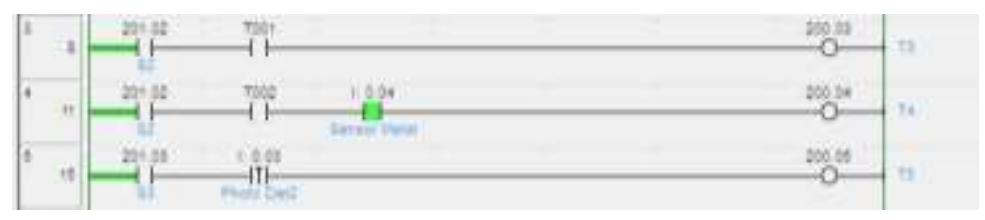

Gambar 20. Diagram ladder pada saat sensor metal mendeteksi logam

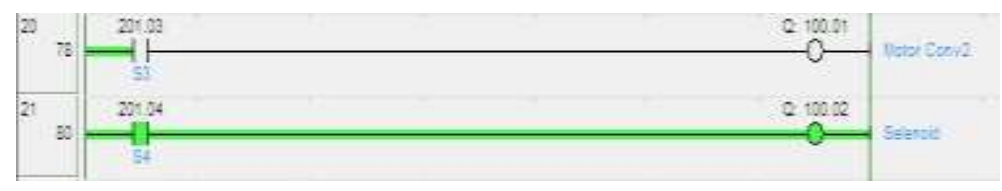

Gambar 20. Diagram ladder pada saat selenoid bekerja 


\section{KESIMPULAN}

1. Dari hasil pengukuran dan perhitungan terdapat sedikit perbedaan antara hasil pengukuran dan hasil sebenarnya, dengan persentase error antara 0,25 persen sampai dengan 0,29 persen.

2. Dari hasil pengujian sistem bekerja dengan baik sesuai dengan apa yang diinginkan dimana dengan input sensor proximity dan photodetektor sistem dapat memilah antara benda logam dan bukan logam.

3. Proximity sensor akan memberikan sinyal 24 Volt jika tidak mendeteksi benda logam dan 0 Volt bila mendeteksi benda logam, begitupula dengan Photoelectric sensor akan memberikan sinyal 24 volt jika tidak mendeteksi benda dan 0 volt bila mendeteksi benda.

\section{DAFTAR PUSTAKA}

[1] Alimuddin.ST.MT. 2016. Diktat Pelatihan PLC (Programmable Logic Conntroller. Politeknik Katolik Saint Paul Sorong.

[2] Ahrani, Suci Robbi. 2014. Rancang Bangun Conveyor Pengisian Air Otomatis Dengan Input Sensor Optical Proximity. Politeknik Negeri Sriwijaya, Palembang.

[3] Corporation, OMRON. "Sysmac CPIL/CPIE Introducation CPU Unit Manual" (China : OMRON, 2009).

[4] Desiani. 2015. Aplikasi Sensor Proximity Pada Lengan Robot Sebagai Penyortir Kotak Berdasarkan Ukuran Berbasis Arduino Uno. Politeknik Negeri Sriwijaya, Palembang.

[5] Guntoro, Helmi..2013. Rancang Bangun Magnetic Door Lock Menggunakan Keypad Dan Solenoid Berbasis Mikrokontroler Arduino Uno. PTK Universitas Pendidikan Indonesia. Electrans,Vol 12, No.1, 20 November 2018.

[6] Raharjo, Rudianto.2013, Rancang Bangun Belt Conveyor Trainer sebagai Alat Bantu Pembelajaran. Jurnal Teknik Mesin Volume 4, No. 2. https://psppmpk.files.wordpress.com/2014/11/jurnal-teknik-mesin-volume-4-nomor-2-tahun2013.pdf, diakses 20 November 2018.

[7] Setiawan, Iwan. 2009. Buku Ajar Sensor dan Tranduser. Universitas Diponegoro. http://eprints.undip.ac.id/4886/1/Sensor_dan_Transduser.pdf, diakses 20 November 2018 